\title{
Solubilización de fosfatos: una función microbiana importante en el desarrollo vegetal
}

\author{
Lucía Constanza Corrales Ramírez, MSc ${ }^{1}$ \\ Zuly Yurieth Arévalo Galvez ${ }^{2}$, Vanessa Estefanía Moreno Burbano ${ }^{2}$
}

1. Docente investigadora. Universidad Colegio Mayor de Cundinamarca. Bogotá, Colombia.

2. Estudiantes Programa de Bacteriología y Laboratorio Clínico, Facultad de Ciencias de la Salud. Universidad Colegio Mayor de Cundinamarca. Bogotá, Colombia.

Correspondencia: 1corralesr07@gmail.com

Recibido: 25/03/2014 Aceptado: 10/06/2014

\section{Resumen}

La agricultura es la base fundamental para la sostenibilidad de la seguridad alimentaria en el planeta, ya que representa la principal fuente de alimento y hace parte de la economía de los países en desarrollo. Sin embargo en la actualidad la demanda de alimento es mayor y existe la necesidad de agilizar el crecimiento vegetal para suplir las necesidades de la población y disminuir los índices de desnutrición y hambre, pero para ello se utilizan prácticas agrícolas como la aplicación de fertilizantes químicos que afectan significativamente el medio ambiente y los ecosistemas del suelo. En busca de encontrar soluciones, en los últimos años se han desarrollado estrategias alternativas para reemplazar los fertilizantes. Los microorganismos han demostrado cumplir funciones que mantienen el equilibrio del suelo y apoyan el crecimiento vegetal mediante diversos mecanismos, entre ellos la solubilización de fosfatos, por el cual se logra liberar el ion fosfato accesible para la planta. Este elemento se encuentra limitado en el suelo y es un nutriente vital después del nitrógeno para el desarrollo de la planta. El género Bacillus se ha destacado como un potencial solubilizador de fosfato y puede ser utilizado como biofertilizante que va a permitir obtener un producto agrícola de calidad y sin generar consecuencias al ambiente.

Palabras clave: bacterias promotoras de crecimiento, biofertilizante, ecosistema, solubilización de fosfatos.

\section{Solubilization of phosphates: an important microbial function in plant development}

\begin{abstract}
Agriculture is the fundamental basis for the sustainability of food security on the planet, since it represents the main source of food and is part of the economy of developing countries. At the present time, however, the demand for food is greater and there is the need to speed up plant growth to meet the needs of the population and to reduce rates of malnutrition and hunger, but this is used for agricultural practices as the application of chemical fertilizers which significantly affect the environment and the ecosystems of the soil. In hopes of finding solutions, alternative strategies to replace fertilizers have been developed in recent years. The microorganisms have demonstrated compliance functions that keep the balance of the soil and support plant growth through a variety of mechanisms, including the solubilization of phosphates, which can succeed in freeing the phosphate ion accessible for the plant. This item is limited in the soil and is a vital nutrient after the nitrogen for the growth of the plant. The genus Bacillus has been highlighted as a potential solubilizer phosphate and can be used as biofertilizer that will enable them to obtain a quality agricultural product, without generating consequences to the environment.
\end{abstract}

Key Words: bacteria growth promoters, biofertilizer, ecosystem, solubilization of phosphates. 


\section{Introducción}

En la actualidad el hambre es un problema de magnitud mundial que conlleva al aumento y propagación de enfermedades en la población como consecuencia de la desnutrición, es por esta razón que la Organización de las Naciones Unidas (ONU) propuso ocho objetivos para el presente milenio, entre ellos erradicar la pobreza extrema y el hambre (1). En Colombia la calidad de vida y las condiciones económicas de la mayoría de los habitantes contribuye a mantener esta condición. Actualmente existe la necesidad sentida de cubrir la demanda de alimentos en el planeta mediante producción eficiente y limpia que permita una sostenibilidad en la oferta de vegetales a largo plazo.

Por otro lado, los agricultores recurren a fertilizantes químicos poco convenientes con el medio ambiente para suplir los requerimientos de la planta que no obtienen del suelo y lograr mayor productividad, este tipo de productos son utilizados sin conocer las condiciones óptimas para su aplicación, como las características del suelo y tipo de cultivo. Es importante resaltar que el uso de fertilizantes tiene como objetivo no sólo maximizar los beneficios en la producción agrícola, sino proteger el medio ambiente (2). De igual forma hay que considerar que el alto consumo de fertilizantes genera un gasto representativo para la economía, que en muchas ocasiones no es recuperado con la cosecha (3).

Los avances de la biotecnología han permitido encontrar soluciones eficaces con el fin de reemplazar fertilizantes químicos con la utilización de microorganismos, es el caso del potencial de algunas bacterias que actúan como mediadores, puesto que logran liberar iones de diversos elementos como nitrógeno, potasio, azufre, calcio, magnesio y fósforo, siendo este último un nutriente esencial para la planta. Los mecanismos de solubilización con que cuentan los microorganismos facilitan la absorción de todos los compuestos incluido el fósforo; además las bacterias en particular cumplen funciones vitales para el sostenimiento del suelo como ecosistema, que son de gran interés para la producción agropecuaria, que se traducen en el aumento del rendimiento de los cultivos, sin causar daños al medio ambiente y conservando el equilibrio de los ecosistemas (4).

\section{EL suelo como ecosistema}

El suelo es un cuerpo natural que cubre la mayor parte de la superficie terrestre, posee las condiciones adecuadas para que exista una gran diversidad microbiana capaz de realizar procesos que ayudan al sostenimiento del mismo. Se encuentra conformado por rocas y capas de otros elementos como el humus, arcilla y arena, donde se desarrollan la mayor parte de los ciclos vitales microbianos, además es una importante fuente de macro y micronutrientes (5). Entre las funciones del suelo están: actuar como regulador del ciclo del agua, con capacidad de retener sustancias y favorecer la transpiración de aire a través de la superficie, y actuar como amortiguador frente a agentes nocivos (6). Estas condiciones en el suelo hacen posible la presencia de diferentes microorganismos que por las funciones metabólicas que cumplen aumentan la cantidad de nutrientes asimilables para la planta, fortalecen la relación simbiótica con la raíz de la planta y por ende facilitan el crecimiento vegetal.

La creciente degradación de los suelos disminuye el rendimiento de la producción agrícola así como la actividad humana que lleva a procesos como la erosión, la deforestación y la contaminación de los ríos, obteniendo productos agrícolas de baja calidad y por ende baja productividad desde el punto de vista económico, y que al final no logran suplir las necesidades de alimento que la sociedad demanda (7). Con el fin de contribuir a combatir esta problemática y agilizar el crecimiento vegetal, los agricultores utilizan de forma indiscriminada fertilizantes químicos que dañan el suelo acumulándose como sales que evitan el intercambio catiónico y deterioran la calidad del mismo (1), optar por alternativas biológicas mejoraría notablemente el rendimiento de las cosechas y garantizaría la protección del medio ambiente. 


\section{La solubilización de fosfato ¿Una nueva alternativa biológica?}

La solubilización de fosfatos es una de las funciones que se ha convertido en tema de investigación por su importancia para la agricultura. Entre los géneros bacterianos que poseen esta cualidad se destacan Bacillus sp, Stenotrophomonas sp, Burkholderia sp, Pseudomonas sp, Rhizobium sp, Vibrio proteolyticus, Enterobacter aerogenes y Streptomyces sp, entre otros (4). La presencia de estas bacterias en el suelo aumentan la cantidad de diferentes iones, uno de éstos es el fósforo que al ser hidrolizado con enzimas como los fitasas, facilitan la movilidad de este elemento en el suelo y lo transforman en un compuesto accesible para la planta (8).

\section{El fósforo y su importancia}

El fósforo es uno de los requerimientos esenciales para el crecimiento y funcionamiento de la planta, éste se encuentra involucrado en el desarrollo de la raíz y del grano, en el crecimiento y la floración, además se encuentra constituyendo los fosfolípidos de las membranas celulares y del material genético; cumple funciones en el metabolismo energético celular y en procesos de fotosíntesis, glucólisis, respiración y síntesis de ácidos grasos (9).

El fósforo es uno de los elementos vitales para el desarrollo vegetal, sin embargo, este se encuentra en baja disponibilidad en la corteza terrestre debido a que la movilidad en el suelo es restringida, de tal forma que la planta absorbe el elemento de su entorno específico en mínimas cantidades, esta condición natural ha generado interés por encontrar alternativas que faciliten la absorción de éste por las raíces de las plantas y así incrementar la concentración disponible en la rizósfera (10).

En diferentes ecosistemas la reserva de fósforo se encuentra en las rocas, unido al oxigeno formando fosfatos. Cuando las rocas están expuestas al ambiente, la intemperie y la lluvia, estos fosfatos se disuelven, de tal forma que son absorbidos fácilmente a través de las raíces de la planta. La cantidad de fósforo en el suelo se expresa como $\mathrm{P}_{2} \mathrm{O}_{5}$ y este se clasifica en fósforo inorgánico y fósforo orgánico (9).

\section{Fósforo inorgánico}

Está representado por el fósforo presente en minerales primarios como las apatitas, hidroxiapatitas y oxiapatitas, este no es asimilable por las plantas ya que es insoluble y difícilmente solubilizable, por ello realiza procesos de intercambio a una velocidad muy lenta. Algunas bacterias solubilizan el fósforo inorgánico a través de la producción de ácidos orgánicos, como ácido glucónico el cual libera fosfatos y cationes al suelo que son fácilmente asimilables $(4,11,12)$.

\section{Fósforo orgánico}

Las principales formas del fósforo orgánico son el fosfato de inositol, los ácidos nucleicos y fosfolípidos. El fósforo orgánico que se encuentra principalmente en restos vegetales y animales, es degradado por los microorganismos presentes en el suelo, estos hidrolizan el fósforo orgánico mediante enzimas, liberando el fosfato, el cual es asimilable por las plantas $(4,13)$.

\section{Ciclo del fósforo}

Como se observa en la figura 1 , el depósito principal está constituido por rocas fosfóricas. El ciclo comienza con los iones de fosfatos disueltos, las plantas lo absorben a través de sus raíces y lo distribuyen en todas las células. A su vez, los animales lo adquieren al ingerir los vegetales. Al morir las plantas y los animales a través de sus excretas liberan fósforo insoluble y las bacterias que solubilizan fosfato transforman el fósforo en fosfatos inorgánicos disueltos, una parte de dichos fosfatos son arrastrados al mar, los cuales descienden hasta el fondo y forman rocas, la otra parte de estos fosfatos lo toman las algas, las aves marinas y los peces siendo finalmente ingeridos por los seres humanos con lo cual se completa el ciclo $(14,15)$. 


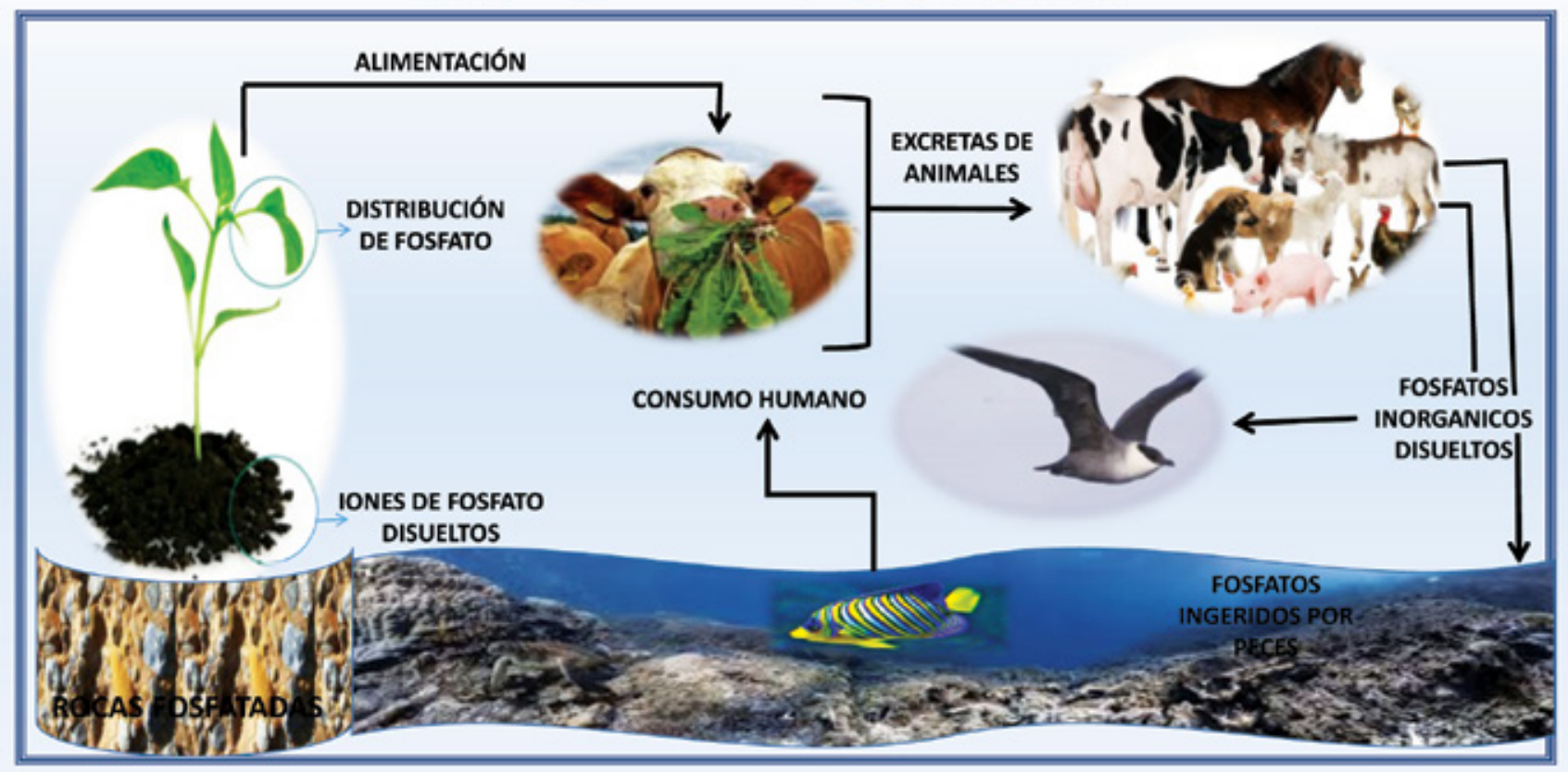

Figura 1. Ciclo del fósforo. Arévalo, Moreno, (2013).

\section{Mecanismos de solubilización de fosfato en el suelo}

\section{Producción de ácidos orgánicos}

Desde 1908 se ha reportado que la solubilización de fosfatos se debía a la producción extracelular de ácidos orgánicos, los cuales, entre otras funciones, intervienen en la quimiotaxis microbiana y detoxificación de los metales. Los ácidos orgánicos son compuestos de bajo peso molecular, entre los que se encuentran: ácido butírico, oxálico, succínico, málico, glucónico, acético, láctico, cítrico, fumárico, 2-cetoglucónico, los cuales actúan sobre compuestos insolubles de fosfato inorgánico como: fosfato dicálcico, fosfato tricálcico, y roca fosfórica (hidroxiapatita, apatitas, fluorapatita, cloroapatita). La presencia de ácidos orgánicos permiten la acidificación del suelo facilitando la absorción de este elemento, poseen carga negativa formando complejos al quelar los iones metálicos como el $\mathrm{Ca}^{+^{2}}, \mathrm{Mg}+^{2}, \mathrm{Fe}+{ }^{3}$ y $\mathrm{Al}_{+}^{3}$ que se encuentran asociados con fósforo insoluble y se transforman en fósforo soluble para la planta (16). Por reacciones químicas las bacterias son capaces de convertir el fosfato tricalcico $\mathrm{Ca} 3\left(\mathrm{PO}_{4}\right)_{2}$ en fosfato di y monobásicos asimilables para las plantas. Muchas bacterias utilizan la ruta metabólica de la glucosa para la producción de estos ácidos, provocando la liberación del fósforo al medio (16).

\section{Ca3 $\left(\mathrm{PO}_{4}\right)_{2}+\mathrm{C}_{2} \mathrm{O}_{4} \mathrm{H}_{2} \longrightarrow 2 \mathrm{CaHPO}_{4}+\mathrm{Ca}_{2} \mathrm{O}_{4}$ \\ Fosfato tricálcico + Acido oxalico $\longrightarrow$ Fosfato dicalcico+oxalato de Ca}

Figura 2. Solubilización de fosfatos inorgánicos. Imagen tomada de Plazas (2007).

Las bacterias que se asocian con la producción de ácidos orgánicos que solubilizan fosfato son generalmente Rizobacterias entre las que se encuentran: Bacillus, Pseudomonas, Burkholderia, Agrobacterium, Flavobacterium, Rhizobium, Yarowia, Streptosporangium, Aerobacter, Achromobacter $y$ Erwinia. Sashidhar B. describe la enzima de la glucosa deshidrogenasa en la vía de oxidación directa (DO), la cual se encuentra involucrada en el proceso de la solubilización de fosfato mineral en bacterias Gram negativas. 
La solubilización de fosfato se da como resultado de la acidificación del espacio periplásmico por los ácidos producidos de la DO de la glucosa y otros azúcares aldosa reductasa por la glucosa deshidrogenasa. Entre los ácidos que se producen por esta vía se encuentran: ácido acético, láctico, málico, succínico, tartárico, oxálico y ácido cítrico, siendo los más fuertes los ácidos glucónico y 2-cetoglucónico capaces de actuar como quelantes de $\mathrm{Ca}+{ }^{2}$ en condiciones apropiadas y acidifican el medio, necesario para la disolución de fosfatos de calcio (Fosfato tricálcico o hidroxiapatita), además de ser importante en el metabolismo intracelular de las bacterias, entre las que se destacan Achromobacter, Agrobacterium, Bacillus, Enterobacter, Erwinia, Escherichia, Flavobacterium, Mycobacterium, Pseudomonas y Serratia.

El estudio sugiere que el sistema de la vía de oxidación para el metabolismo de la glucosa deshidrogenasa puede ser manipulada genéticamente al transferir los genes codificantes a otros microorganismos para que puedan actuar como potenciales solubilizadores de fosfato y sean aplicados en la agricultura (17). Las cepas del género Bacillus como Bacillus liqueniformis y Bacillus amyloliquefaciens emplean rutas como la glicolisis siendo esta la fermentación láctica primaria para la obtención de ácidos orgánicos como el láctico, también usan otras rutas como la oxidación anaerobia del piruvato adquiriendo acido butírico. Otras bacterias solubilizadoras como Bacillus megaterium dispone de rutas como la de ácidos tricarboxílicos sintetizando el ácido málico, y rutas como la oxidación directa de la glucosa son tomadas por bacterias como Bacillus firmus obteniendo acido 2-Cetoglucónico.

En 1992 un estudio evidenció que al realizar acidificación artificial del medio con $\mathrm{HCl}$ se produjo una menor actividad solubilizadora de fosfato en comparación con la obtenida mediante actividad microbiana, sin embargo, el tipo y la cantidad de ácido dependen de cada microorganismo, aunque su principal fuente es la descomposición de materia orgánica, el papel de los ácidos orgánicos en estos procesos sigue siendo desconocido (18).

\section{Producción de enzimas fosfatasas}

Las fosfatasas son producidas por algunos microorganismos y su liberación se estimula en condiciones específicas como la disponibilidad de materia orgánica, humus, estiércol, residuos vegetales, coloides, así como el bajo nivel de fósforo en el suelo. Estos componentes protegen las enzimas y persisten por largos periodos de tiempo, pero cambios bruscos en el $\mathrm{pH}$ puede llegar a desnaturalizarlas e inactivarlas (4).

El proceso de solubilización consiste en la hidrólisis de enlaces éster del fosfato orgánico, las cuales se dividen en monoéster fosfato hidrolasa, di-éster fosfato hidrolasa, tri-éster fosfato hidrolasa. En el grupo de las monoester fosfato hidrolasa se encuentran las fosfatasas ácidas y fosfatasas alcalinas que actúan respectivamente según el $\mathrm{pH}$ en el que se encuentre en el suelo ( $\mathrm{pH} 4-9$ ), estas aumentan la disponibilidad de fósforo inorgánico soluble para las plantas, y son las bacterias las que realizan este proceso bioquímico como mecanismo de supervivencia. La descomposición de la materia orgánica en el suelo se logra por acción de las bacterias que liberan el ion ortofostato desde estructuras unidas al carbono como se muestra en la Figura 3.

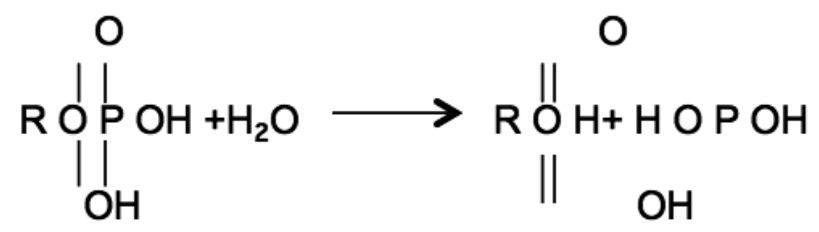

Figura 3. Acción de las fosfatasas. Imagen Tomada de Plazas 2007.

Según estudios previos las bacterias reportadas como productoras de fosfatasas son Pseudomonas, Bacillus, Burkholderia y Pantoea (19). 


\section{Producción de enzimas fitasas}

Son un tipo de fosfatasas producidas por microorganismos como Bacillus sp., los cuales permiten la liberación del fósforo insoluble a partir de la hidrólisis de fitatos que se encuentran en el ácido fítico (hexafosfato de inositol) disponible en el suelo. Por otro lado, el ácido fítico facilita que en las semillas de las plantas se almacenen iones $\mathrm{de}_{\mathrm{Mg}+}{ }^{2}$ y $\mathrm{K}+$ y en menor proporción de $\mathrm{Ca}+{ }^{2}, \mathrm{Mn}+{ }^{2}, \mathrm{Ba}+{ }^{2}, \mathrm{y}$ $\mathrm{Fe}+{ }^{2}$. Estas enzimas se encuentran distribuidas en las plantas, tejidos de animales y microorganismos de los cuales se han reportado bacterias Gram negativas como Klebsiella, Pseudomonas y E.coli.

En la actualidad las fitasas son de gran interés biotecnológico por su aplicabilidad en el mejoramiento de cultivos, entre los mecanismos más comunes se encuentran la producción de fosfatasas ácidas por la presencia de sustratos específicos en el suelo (20). Es probable que estas enzimas estén reguladas por la expresión de genes que codifican su función en la mineralización de fósforo, lo que constituiría la base para futuras investigaciones, al desarrollar y crear vectores para transferencia de genes en microorganismos que no tengan la capacidad de solubilización $(21,22)$.

En la revisión documental realizada por H. Rodríguez y colaboradores en el año 2006 se demuestra la importancia sobre la inserción de genes codificantes para la mineralización del fósforo, mediante ADN recombinante en microorganismos que no poseen esta capacidad, encontrando esta información genética en diferentes bacterias implicadas en el proceso de solubilización de fosfatos y la relación de ésta función con la secreción de ácidos orgánicos, entre las cuales están: Erwinia herbicola, Morganella morganii, Bacillus subtilis, Pseudomonas sp., Enterobacter sp., Serratia marcescens, Burkholderia cepacia. En el estudio realizado se transfirieron plásmidos de estas bacterias a cepas de E.coli proporcionándole la actividad solubilizadora, y permitiendo abrir nuevas perspectivas sobre la manipulación de estos genes así como su uso efectivo para aumentar la producción agrícola (21).
En otro estudio, realizado por Milko A. Jorquera y colaboradores, se confirma la importancia de las fitasas en el mecanismo de solubilización de fosfato. Las bacterias Gram positivas, del género Bacillus y Paenibacillus, poseen esporas que las hacen resistentes a condiciones adversas, como en suelos de origen volcánico que tienen un $\mathrm{pH}$ altamente ácido y que contienen grandes cantidades de fitato. Estas bacterias son capaces de utilizar el fitato como única fuente de fósforo, ya que son portadores de genes que codifican para las enzimas fitasas y pueden sobrevivir mejor que las bacterias Gram negativas.

Los autores señalan que las fitasas tuvieron una alta actividad en suelos alcalinos lo que corrobora la información sobre la función de la enzima (puede actuar en distintos valores de $\mathrm{pH}$ ). Sin embargo, el estudio explica que el tipo y cantidad de fitasas sí pueden depender del $\mathrm{pH}$ y de las condiciones químicas del suelo; cabe destacar que la composición de la población microbiana también se ve afectada por factores como el tipo de suelo, fertilización, genotipo y edad de la planta. Se ha descrito que la fitasas $\beta$-hélice (BPP) es predominante en el género Bacillus y considerada como la más importante en el proceso de la función solubilizadora de fosfato (23).

\section{Bacillus}

Es el género más representativo del grupo de solubilizadores de fosfato, se encuentra presente en el suelo, agua, vegetales y aire, poseen diversos mecanismos de supervivencia como la formación de esporas centroméricas ante situaciones adversas, hasta encontrar las condiciones favorables para su crecimiento, con una gran capacidad metabólica que conlleva a que su colonización en la rizósfera sea exitosa $(24,25)$.

Son bacterias Gram positivas pertenecientes a la familia Bacillaceae, tienen forma de bastón y su tamańo varia de $0.5 \times 1.2$ a $2.5 \times 10 \mu \mathrm{m}$ con terminaciones cuadradas que se disponen en largas cadenas, aerobios o anaerobios facultativos, móviles 
con flagelos laterales, saprofitos, la mayoría de las especies presentan catalasa positiva, su crecimiento se desarrolla favorablemente en ambientes con $\mathrm{pH}$ ácido y básico entre un rango de $(5.5-8.5)$ y a diferentes temperaturas $\left(-5^{\circ} \mathrm{C}\right.$ a $\left.75^{\circ} \mathrm{C}\right)$, en agar sangre se observa hemólisis variable, sus características fenotípicas son colonias grandes, con bordes irregulares de color blanco a grisáceo (26).

Entre las especies potencialmente solubilizadoras se encuentran: Bacillus licheniformes, B. pumilus, $B$. subtilis y B. brevis (27). Algunas bacterias pertenecientes a este género hacen parte de la flora normal de humanos y animales y otras son patógenas causando generalmente intoxicaciones alimentarias (26). El género Bacillus sp. es un referente de investigación puesto que representa una amplia aplicabilidad en el campo biotecnológico por sus diferentes usos industriales y ambientales (27).

Un ejemplo de lo anterior se presenta en el trabajo de P. Díaz Vargas et al, en el año 2001 quienes investigaron sobre la importancia de la utilización de bacterias promotoras de crecimiento vegetal en cultivos de lechuga. En este estudio se destacaron los géneros: Pseudomonas, Mycobacterium, Micrococcus, Bacillus y Flavobacterium por la capacidad de usar mecanismos como la movilización de nutrientes solubles, y la solubilización de algunos compuestos como el fósforo a formas que son asimilables y disponibles para la planta. En dicho estudio se evaluó el efecto de 30 cepas bacterianas durante las fases de germinación y crecimiento de los cultivos.

El estudio inicia con la inoculación de las semillas de la lechuga y la suspensión bacteriana en cajas de Petri, encontrando que el $76.6 \%$ de las cepas incrementaron la germinación, la estimulación foliar y el incremento en el peso fresco de la planta, mientras que el $10 \%$ no tuvieron efecto y un $13.3 \%$ redujeron las condiciones de crecimiento (28). El uso del medio selectivo Pikovskaya (PKV) que contiene fosfato tricálcico (TCP), ha permitido identificar la formación de halos de solubilización que se evidencia por la acidificación del medio (viraje a amarillo) cuando las bacterias u hongos hacen uso del fosfato como única fuente nutritiva $(29,30)$. Chen Y.P y colaboradores, en el 2006, usaron este medio de cultivo para identificar bacterias potencialmente solubilizadoras de fosfato aisladas de suelos cubiertos con vegetación nativa, en el cual se observó la formación de un halo claro alrededor de las UFC como indicador de la utilización del fósforo, las colonias en las cuales se evidenció el halo fueron purificadas mediante resiembra en un agar con TCP, posterior a esto, a las cepas seleccionadas se les realizó identificación y análisis filogenético mediante secuenciación de rDNA 16S, dando como resultado 10 aislamientos pertenecientes al género Bacillus, 9 para Rhodoccoccus, 7 de $A r-$ throbacter, 6 de Serratia y un aislamiento para Chryseobacterium, Delftia, Gordonia y Phyllobacterium, confirmando en el estudio a estas últimas cepas como "nuevas" bacterias solubilizadoras de fosfatos, además se asoció ésta función con la secreción de ácidos orgánicos que a través de los grupos hidroxilo y carboxilo quela los iones unidos al fósforo convirtiéndolo en forma soluble para la planta. Por medio de cromatografía liquida de alta resolución (HCLP) se determinó la presencia de los ácidos cítrico, glucónico, láctico, succínico, propiónico y 3 ácidos desconocidos como indicadores de la función solubilizadora de fosfato, y en 3 cepas que no produjeron ácido la solubilización del fosfato fue mínima (31).

Los biofertilizantes a base de microorganismos benéficos han sido objeto de investigaciones puesto que su aplicabilidad en los suelos presenta una mayor eficacia y la planta puede disponer de mayor fósforo soluble (32-34). Esta alternativa minimiza notablemente el impacto ambiental que producen los fertilizantes químicos, mejorando el rendimiento de los cultivos y limitando el uso de estos productos tóxicos para el suelo que conllevan a su erosión (35-37). 
M. López et al, durante el 2008, evaluó el efecto de biofertilizantes bacterianos sobre el crecimiento en cultivos de maíz, y demostró la capacidad de algunas bacterias como Bacillus megaterium y Azotobacter sp, de solubilizar compuestos como el fósforo. En el estudio se utilizaron dos tipos de suelos provenientes de ecosistemas venezolanos, un suelo de alta fertilidad natural (A) y el otro de baja fertilidad natural (B). Las cepas utilizadas fueron obtenidas de un ecosistema de sorgo-frijol del estado Guárico. El aislamiento de las cepas solubilizadoras de fósforo (SF) se realizó en medio de cultivo Pikovskaya, incubándose durante 5 días con la obtención de colonias que formaron un halo transparente, dichas cepas fueron utilizadas para preparar el biofertilizante que fue aplicado como solución nutritiva; de las cepas utilizadas, 10 mostraron un alto índice de solubilización de fosfato.

Posteriormente, se realizó la identificación de las 10 cepas bacterianas obtenidas en los suelos en la zona alrededor de las semillas de maíz en los suelos A y B y se evidenció el efecto biofertilizante sobre la germinación y la precocidad del desarrollo del maíz. Sin embargo, el crecimiento fue diferente por la disponibilidad de nutrientes del suelo, siendo más efectivo el biofertilizante en el suelo A $(38,39)$.

En el año 2012 Tripti, Vipin Kumar y Anshumali relacionan otros microorganismos con capacidad solubilizadora de fosfatos. En su estudio se evaluaron un total de 50 cepas agrícolas de DhanbadIndia, las cuales fueron cultivadas y mediante caracterización morfológica y pruebas bioquímicas se identificó la presencia de Pseudomonas sp, Azotobacter sp, y Bacillus sp. Para llevar a cabo el análisis de la actividad solubilizadora de fosfato se utilizaron la medición cuantitativa y la cualitativa. En la medición cuantitativa se encontró que todas las cepas seleccionadas mostraron un halo claro alrededor de las colonias, de las 10 cepas aisladas las bacterias del género Pseudomonas sp. y Bacillus sp. revelaron la actividad máxima de solubilización de fosfato con un índice de solubilización de 3,1 y 3,0, con una variación en el tamaño del halo de 2,0 a 5,0 mm en agar PVK. En cuanto a la medición cualitativa, se demostró que las 10 cepas aisladas fueron capaces de solubilizar fosfato tricálcico (TCP) lo que indica la producción de múltiples ácidos orgánicos. Concluyendo que el uso de estas cepas nativas como biofertilizantes ayuda a reducir el uso de fertilizantes químicos, el costo del cultivo y por otro lado contribuye al mantenimiento de la fertilidad del suelo (40).

En el trabajo de Usha Seshachala et al, en 2012, realizado en la India, también se evidencia el uso del medio Pikovskaya, En este estudio se aislaron microorganismos (bacterias y hongos) de la rizósfera de un cultivo de pimienta; una especia muy apetecida en todo el mundo. El aislamiento en el medio Pikovskaya indico la presencia de diferentes géneros bacterianos Pseudomonas, Bacillus, Streptomyces, Actinomicetos, Arthrobacter. En la investigación se puso a prueba la solubilización de diferentes fuentes de fosfatos inorgánico entre ellos: fosfato de roca (RP), fosfato tricálcico (TCP) y fosfato de hidrógeno de potasio (KHP) a diferentes concentraciones 2.5, 5.0 y $7.5 \mathrm{gl}^{-1}$ demostrando la máxima solubilización por diversas especies de Bacillus, entre ellas B. subtilis ( $86 \mathrm{~mm}$ ) y dentro del grupo de los hongos Aspergillus niger (26,3mm). Estas cepas fueron capaces de solubilizar TCP, KHP y RP de manera eficiente a una concentración de $5.0 \mathrm{gL}^{-1}$. Por la importante función que cumplen estos microorganismos se ve la oportunidad de utilizarlos como abonos fosfata$\operatorname{dos}(41)$.

Pablo Álvarez Figueroa y Sady García Bendezú en el mismo año también señalan la importancia del medio Pikovskaya (PVK) para la identificación de cepas promisorias como solubilizadoras de fosfato. En su estudio aislaron cepas de suelos calcáreos del Valle del Mantaro pertenecientes a los géneros Pseudomonas sp, Bacillus sp y Clostridium sp y una cepa del hongo 
Penicillium sp seleccionadas por presentar mayor halo de solubilización. La eficiencia fue evaluada en el medio liquido PVK al cual se le agregó fosfato tricálcico y roca fosfórica de Bayovar, una reserva de depósitos sedimentarios en Perú. En el trabajo se determinó que la concentración de fósforo solubilizado es inversamente proporcional al $\mathrm{pH}$, observándose que a valores bajos (el mínimo 3.72) Pseudomonas liberó fósforo a partir de la roca fosfórica. De igual forma se concluyó en este estudio que la solubilización de fosfato fue mayor a partir de fosfato tricálcico que de roca fosfórica puesto que es un compuesto de más difícil solubilización. Las bacterias del estudio demostraron tener mayor índice y halo de solubilización con respecto a los hongos. Clostridium sp. fue la cepa con mayor eficiencia de solubilización in vitro, mientras que Penicillium sp. resultó en los valores más bajos a partir del fosfato tricálcico (42).

Se han propuesto métodos para cuantificar con mayor precisión la solubilización de fosfato como se muestra en el trabajo de Rodríguez Gámez, Odalys y colaboradores en el cual describen el método colorimétrico $\mathrm{Mo}$-blue o del ácido ascórbico para cuantificar los iones ortofosfato resultado del proceso de solubilización de fosfato. Se propuso este método ya que algunas cepas no presentan halo claro de solubilización en medio solido pero si son capaces de solubilizar fosfatos inorgánicos insolubles en medios líquidos. Se utilizaron cepas de Bacillus aisladas de suelo de la rizósfera de caña de azúcar para comprobar la efectividad del método. El fósforo soluble obtenido a partir de fosfato tricalcico en el medio líquido, oscilo entre 100 y $300 \mu \mathrm{g} / \mathrm{mL}$ y determinaron que el micro método puede emplearse en muestras cuya concentración de fósforo soluble se encuentre por encima de $0,27 \mu \mathrm{g} / \mathrm{mL}$, logrando una exactitud a un $95 \%$ de muestras cuya concentración sea igual o mayor a $0,9 \mu \mathrm{g} / \mathrm{mL}$, lo que confirma que es posible cuantificar la solubilización de fosfato soluble en cultivos microbianos (43).

\section{El gen Phy y su relación con la función solubilizadora de fosfato}

En la actualidad, la biología molecular ha sido de gran utilidad para el desarrollo de nuevas investigaciones, la identificación de los genes que codifican la solubilización de fosfatos ofrece nuevas perspectivas en el sector agrícola. Las enzimas fitasas tienen un gran valor comercial como suplemento para alimentos de aves de corral y cerdos. Obtener una cantidad favorable de esta a partir de cepas de Bacillus (44) es una forma rentable en el apoyo de procesos como la solubilización de fosfatos al poder clonar y transferir los genes a microorganismos que carecen de esta función y realizar inóculos de bacterias en gran cantidad para que el proceso sea más eficiente y exitoso. Existen 2 tipos de fitasas; las fitasas acidas y fitasas alcalinas además son altamente termoestables. Por lo general, las fitasas ácidas son las más utilizadas como complemento alimentario porque pueden liberar fósforo inorgánico a partir de las dietas, bajo condiciones ácidas durante el proceso de digestión de los animales, evitando contaminación ambiental por la eutrofización de las aguas (20). Según diferentes estudios el género Bacillus es el más apropiado para obtener fitasas óptimas en éstos procesos.

En el estudio de R. Bawane y colaboradores desarrollado en el 2011 aislaron el gen Phy de dos cepas de Bacillus subtilis NCDC-070 y NCIM-2712 y el producto de la clonación del gen se transfirió a una cepa de E. coli JM-109, en la que se confirmó la presencia de la inserción del gen mediante secuenciación. Al realizar una comparación sobre la presencia del gen Phy en cepas de referencia de Bacillus con las secuencias del gen Phy obtenidas de las bacterias en el estudio, se demostró, mediante el análisis filogenético, la relación entre el gen Phy de las cepas Bacillus (NCDC-070 y NCIM-2712) y las otras secuencias de genes Phy de la base de datos. Por otro lado, se observó que la secuencia del gen Phy, obtenida de la base de datos, mostraron 98\% de homología con el Bacillus spp aislado en el estudio y sólo $91 \%$ de homología con la B. subtilis (45). 


\section{Otros genes involucrados en la solubilización de fosfato}

En el estudio de Haike Antelmann et al, en el año 2000 , se analizó la respuesta de $B$. subtilis a la necesidad del requerimiento del fosfato, demostrando la inducción de algunos regulones, específicamente el regulon Pho el cual se expresó debido al estrés ambiental, generando proteínas dependientes de dicho regulon. Estas proteínas participan en la protección del ADN y de las membranas, además contribuyen en la supervivencia de condiciones ambientales extremas como el calor osmótico y el estrés oxidativo. Dichas proteínas o genes del regulon Pho son expresadas como sistemas reguladores PhoP / PhoR los cuales permiten utilizar los recursos limitados del fosfato de una manera eficiente. El gen phoD también expresado por el regulon Pho se identificó como responsable de la síntesis de ácido teicuronico el cual sustituye al ácido teicoico en las paredes celulares, dicho acido se expresa cuando PhoP / PhoR son reprimidos. Durante el estudio se encontró que la mayoría de los genes del regulon Pho fueron identificados en el citoplasma y en el proteoma extracelular (46).

Durante el mismo año, Denis Robichon, Maryvonne Arnaud, et al, demostraron que en condiciones de insuficiencia del fosfato B. subtilis realiza la expresión de otros genes tales como PhoA y PhoB, fosfatasas alcalinas del sistema de transporte de fosfato inorgánico, las cuales se activan por componentes (PhoP / PhoR) reguladores de la respuesta del sistema histidina quinasa. Además, se encontró un único promotor, el gen ykol; implicado en la activación de la transcripción, indicando que su expresión fue inducida por la limitación de fosfato, sin embargo, este dependía de los componentes del sistema de regulación PhoP / PhoR (47).

En el trabajo realizado por Zoltan Pragai et al, en 2001, evidenciaron que durante el estrés que produce la limitación de fosfato, bacterias como Bacillus subtilis responden activando algunos genes como los del regulon $\mathrm{PhO}$, permitiendo que la célula transporte y utilicé el fosfato de manera más eficiente, aumentando de esta manera la accesibilidad de las fuentes de fosfato alternativas. Los genes del regulón $\mathrm{PhO}$ que son inducidos en respuesta son el gen phoA y gen phoB, los cuales codifican para fosfatasas alcalinas (48).

En el año 2005, Nicholas E, E. Allenby et al, desarrollaron un estudio de Bacillus subtilis, informando que este tipo de bacterias que se encuentran en el suelo han evolucionado fisiológicamente en respuesta al estrés ambiental, debido principalmente a la limitación de nutrientes esenciales como el fosfato. B. subtilis expresa la inducción de una variedad de genes con diversas funciones, dichos genes son señalados como el estímulo de fosfato (PhO), este incluye 2 regulones PhoP que proporcionan respuesta específica de fosfato cuando inicia el estrés adquiriendo fosfato del medio ambiente, y el regulon SigB quien proporciona protección de los componentes celulares como el ADN y las membranas. Este contiene 100 genes, los cuales prestan protección de los efectos dañinos del estrés, ayudando a la célula a sobrevivir en condiciones potencialmente nocivas. Mientras que el regulon PhoP tiene 34 genes dentro de los cuales hay 5 genes monocistronicos como phoA y ykol (49).

En el año siguiente 2006 Oliwia Makarewicz, Sarah Dubrac, et al, realizaron una investigación dirigida a la fitasa, en este estudio encontraron que varias cepas de Bacillus spp secretaban dicha sustancia; una enzima que cataliza la desfosforilación de myo-inositol (fitato), siendo esta la forma de almacenamiento del fosfato en las plantas, además se evidenció que dicha enzima tiene capacidad para hacer de este fitato fósforo disponible, permitiendo que esta actividad sea llevada a cabo por las bacterias que se encuentran en la rizósfera tales como; Pseudomonas, Klebsiella y Bacillus spp.

Durante el estudio se identificó algunos genes responsables de esta actividad, el gen PhyC de Bacillus amyloliquefaciens fue reconocido como un iniciador 
durante el estrés ambiental en la ausencia de fosfato, pero se demostró que éste se inducia por el sistema de regulación PhoP / PhoR, siendo esencial para iniciar la transcripción del gen PhyC (50).

En otro estudio, realizado en el 2010 por Qinggang Guo et al, se identificaron más de 35 sistemas reguladores en $B$. subtilis, los cuales tienen como función la adaptación al estrés ambiental y la producción de metabolitos secundarios, dichos sistemas de regulación como PhoR / PhoP, corresponden a mecanismos por los cuales $B$. subtilis detecta los estímulos y responde mediante la activación de genes específicos, dichos sistemas participan en procesos como la producción de fosfodiesterasa. Esta enzima se produce cuando el fosfato disponible es una limitación para el crecimiento vegetal, de tal forma que genes específicos como (PhoA, PhoB) específicos en dicha función, son estimulados y activan la recuperación de fosfato inorgánico a partir de fuentes orgánicas (51).

\section{Consideraciones finales}

La alteración del equilibrio en el ecosistema del suelo se debe a la actividad agrícola realizada por el hombre quien en busca de mejorar la productividad de los cultivos utiliza fertilizantes químicos que no solo tienen un impacto negativo en el aspecto ambiental sino también en el económico. Optar por alternativas como los biofertilizantes constituye un aprovechamiento de los microorganismos como Bacillus sp, un género que se caracteriza por ser potencialmente solubilizador de fosfato. El uso de las técnicas de biología molecular permiten manipular genéticamente los microorganismos, ofrece un campo de alternativas para optar por medidas que pueden tener un impacto positivo en el medio ambiente y estrechar aún más la relación simbiótica entre las bacterias y la planta. Sin embargo es necesario obtener mayor conocimiento sobre las características específicas de las bacterias promotoras de crecimiento vegetal para lograr definir las condiciones adecuadas para el desarrollo óptimo del proceso de solubilización del fosfato.
Considerando que el fósforo es un elemento indispensable para el crecimiento vegetal, se ha visto la necesidad de buscar alternativas que permitan el uso eficiente de este nutriente mediante bacterias que logren obtener los iones solubles de fosfato para la planta. El género Bacillus sp ha demostrado ser una excelente alternativa en el proceso de solubilización de fosfato y por esto es recomendable caracterizar su perfil genético, para optimizar su desempeño como biofertilizante. En ese orden de ideas, la agricultura limpia con el uso de biofertilizantes a largo plazo va a permitir recuperar los suelos que hayan sido explotados con malas prácticas agrícolas, logrando minimizar dańos al medio ambiente y a su vez recuperar las propiedades y fertilidad de los suelos y por ende la calidad de los cultivos.

\section{Referencias}

1. Organización de las Naciones Unidas para la alimentación y la agricultura (FAO). Situación alimentaria mundial. Nota informativa de la FAO.2013.

2. Asociación Internacional de la Industria de los Fertilizantes (IFA). Los fertilizantes y su uso. Paris; 2011.

3. Instituto Colombiano Agropecuario (ICA). Subgerencia de Protección y Regulación Agrícola. Boletín técnico: Comercialización de fertilizantes y acondicionadores de suelos; Colombia; 2010.

4. Bobadilla C, Rincón S. Aislamiento y producción de bacterias fosfato solubilizadoras a partir de compost obtenido de residuos de plaza. [Tesis de grado]. Colombia; 2008.

5. Hernández A, Ascanio M, et al. El suelo: fundamentos sobre su formación, los cambios globales y su manejo; 2008.

6. Sistema de información ambiental de Colombia (SIAC). ¿Qué es el suelo y subsuelo? Colombia. Disponible en: https://www.siac. gov.co/contenido/contenido.aspx?catID=744\&conID=1118.

7. Sanzano A. Fosforo del suelo. Química del suelo. [Fecha de acceso 6 de Abril de 2013].URL disponible en: http://www.edafo.com.ar/Descargas/Cartillas/Fosforo\%20del\%20Suelo.pdf.

8. Fernández MT, Rodríguez H. Aplicaciones biológicas de las fitasas: papel en los fertilizantes microbianos. ICIDCA [En línea] 2006 [Fecha de acceso 27 de Enero de 2013]; 11(2).URL Disponible en: http://www.redalyc.org/articulo. oa? id=223120664004.

9. Coyne M, Rasskin M. Microbiología del suelo: un enfoque exploratorio. Espańa: Ed. Paraninfo; 2000.

10. Huilcapi V. Aislamiento e identificación de bacterias fosfato solubilizadoras a partir de muestras de suelo y raíz, de diferentes cultivos de rosas de la provincia de pichincha. [Tesis de grado]. Ecuador; 2007. 
11. Simbaña B. Aislamiento de microorganismos degradadores de fosfatos insolubles. [Tesis de grado] .Ecuador; 2009.

12. Agrolluvia. Portal informativo para el productor agropecuario. Disponible en: http://agrolluvia.com/.

13. Cerón LE, Aristizábal FA. Dinámica del ciclo del nitrógeno y fosforo en suelos. Rev.Colomb.Biotecnol [En línea] 2012[Fecha de acceso 22 de Junio de 2013]; 14(1). URL Disponible en: www.revistas.unal.edu.co/index.php/biotecnologia/article/ view/32889.

14. Universidad Nacional del centro de Perú, Departamento académico de ingeniería química y tecnología. Cátedra Ciencias Ambientales. Ciclo del fosforo; 2011.

15. Universidad Nacional Abierta y a Distancia. Nutrición vegetal. Lección 19. Ciclo del fosforo en la naturaleza; 2011.

16. Plazas EC. Mejoramiento de un medio de cultivo para la producción de un inoculante con base en bacterias fosfato solubilizadoras. [Tesis de grado].Colombia; 2007.

17. Sashidhar B, Podile A.R. Mineral phosphate solubilization by rhizosphere bacteria and scope for manipulation of the direct oxidation pathway involving glucose dehydrogenase. Journal of Applied Microbiology [En línea] 2010 [Fecha de acceso 10 de Marzo de 2014]; 1-12. URL disponible en: http://www. ncbi.nlm.nih.gov/pubmed/20070432.

18. Paredes M, Espinosa VD. Ácidos orgánicos producidos por rizobacterias que solubilizan fosfato: una revisión crítica. Terra Latinoamérica [En línea] 2009[Fecha de acceso 15 de Diciembre de 2012]; 28 (1). URL disponible en: www.buscagro.com/ cgibin/mp/page.cgi?g=Detailed/57922.html.

19. Paredes M. Aislamiento y caracterización bioquímica de metabolitos producidos por Rizobacterias que solubilizan fosfato. [Tesis doctoral].México; 2010.

20. Fernández MT, Rodríguez $\mathrm{H}$. El papel de la solubilización de fosforo en los biofertilizantes microbianos. ICIDCA [En línea] 2005 [Fecha de acceso 2 de Febrero de 2013]; 39(3). URL Disponible en: http://www.redalyc.org/articulo. oa?id=223120688005.

21. Fernández MT, Rodríguez H, González T, Goire I. Construcción de un vector para la integración cromosomal de un gen de fitasa de Bacillus licheniformis. Rev. Peru. biol. [En línea] 2009[Fecha de acceso 11 de Agosto de 2013]; 16(1). URL Disponible en: http://sisbib.unmsm.edu.pe/BVRevistas/biologia/biologiaNEW.htm.

22. Rodríguez H, Fraga R, Gonzalez T, Bashan Y. Genetics of phosphate solubilization and its potential applications for improving plant growth-promoting bacteria. Plant and Soil [En línea] 2006 [Fecha de acceso 2 de Septiembre de 2013]; 102. URL Disponible en: http://link.springer.com/chapter/10.100 7\%2F978-1-4020-5765-6_2.

23. Jorquera Milko A et al. Identication of $\beta$-propeller phytaseencoding genes in culturable Paenibacillus and Bacillus spp. From the rhizosphere of pasture plants on volcanic soils. FEMS Microbiol Ecol [En línea] 2010[Fecha de acceso 12 de Marzo de 2014]; 163-172. URL disponible en: http://www. ncbi.nlm.nih.gov/pubmed/21073489.
24. Layton C, Maldonado E, Monroy L, Corrales L, Sánchez L. Bacillus spp.; perspectiva de su efecto biocontrolador mediante antibiosis en cultivos afectados por fitopatógenos. NOVA [En línea] 2011[Fecha de acceso 3 de Mayo de 2013];9 (15). URL disponible en: http://www.unicolmayor.edu.co/invest_nova/ NOVA/NOVA16_ARTREVIS1_BACILLUS.pdf.

25. Fernández J. Caracterización del proceso de crecimiento de Bacillus subtilis bajo condiciones anaerobias. [Tesis doctoral]. México; 2005.

26. Koneman E, Allen S, Janda W. Diagnostico microbiológico.5ta edición. Madrid- España: Editorial Panamericana; 1999.

27. Arévalo Z, Moreno V. Identificación de la actividad solubilizadora de fosfatos en Bacillus pertenecientes al banco de cepas del grupo Ceparium. [Tesis de grado]. Colombia; 2014.

28. Díaz VP, Ferrera CR, Almaraz J.J, Alcántar G. Inoculación de bacterias promotoras de crecimiento en lechuga. Terra [En línea] 2001 [Fecha de acceso 20 de Octubre de 2013]; 19(4). URL Disponible en:www.chapingo.mx/terra/contenido/19/4/ art327-335.pdf.

29. Calvo P, Zúñiga D. Caracterización fisiológica de cepas de $B a$ cillus spp. aisladas de la rizósfera de papa (Solanum tuberosum). Ecol.apl [En línea] 2010 [Fecha de acceso 17 de Marzo de 2013]; 9 (1). URL disponible en: http://www.scielo.org.pe/scielo.php?pid=S1726-22162010000100004\&script=sci_arttext.

30. Rubio E, Navarrete J, Aguado GA. Caracterización biológica y molecular de bacterias promotoras de crecimiento en vegetales para uso agrario del estado de Guanajuato. XII Congreso Nacional de Biotecnología y Bioingeniería.Mexico.p.1.

31. Chen Y.P,Rekha P.D, Arun A.B, Shen F.T et al. Phosphate solubilizing bacteria from subtropical soil and their tricalcium phosphate solubilizing abilities. Applied Soil Ecology [En linea] 2006 [Fecha de acceso 16 de Agosto de 2013]; 34(1). URL Disponible en: http://www.sciencedirect.com/science/ article/pii/S0929139306000047.

32. Hernández T, Carrión G, Heredia G. Solubilización in vitro de fosfatos por una cepa de Paecilomyces lilacinus. Agrociencia [En línea] 2011 [Fecha de acceso 15 de Agosto de 2013]; 45(8). URL disponible en: http://www.scielo.org.mx/scielo. php?pid=S1405-31952011000800003\&script=sci_arttext.

33. Guevara MF. Aislamiento e identificación de microorganismos solubilizadores de potasio a partir de muestras de suelo y raíces de cultivos de alcachofa de la localidad de la remonta, cantón Cayambe. [Tesis de grado].Ecuador; 2010.

34. Becerra J, Quintero D, Martínez M, Matiz A. Caracterización de microorganismos solubilizadores de fosfato aislados de suelos destinados al cultivo de uchuva (Physalis peruviana L.).Revista Colombiana de ciencias hortícolas [En línea] 2011[Fecha de acceso 10 de Febrero de 2013]; 5 (2.) URL disponible en: http://virtual.uptc.edu.co/revistas2013f/index. php/ciencias_horticolas/article/viewFile/1265/1261.

35. Patiño CO. Solubilización de fosfatos por poblaciones bacterianas aisladas de un suelo del valle del cauca. Estudio de biodiversidad y eficiencia. [Tesis doctoral].Colombia; 2010. 
36. Lara C, Esquivel L, Negrete J. Native phosphate solubilizing bacteria to increase the crops in the department of CordovaColombia. Biotecnología en el sector agropecuario y agroindustrial [En linea]2011[Fecha de acceso 14 de Abril de 2013];9 (2) URL disponible en: http://www.scielo.org.co/scielo.php?script=sci_arttext\&pid=S1692-35612011000200013.

37. Niklitschek MM. Evaluación del rendimiento del trigo (Triticum aestivum), inoculado con bacterias solubilizadoras de fósforo y una cepa fijadora de nitrogeno, aisladas de la rizósfera de especies arbustivas. [Tesis de grado].Chile; 2008.

38. López M, Martínez R, Brossard M, Bolívar A, Alfonso N, Amelia A, et al. Efecto de biofertilizantes bacterianos sobre el crecimiento de un cultivar de maíz en dos suelos contrastantes venezolanos. Agronomía trop [En línea] 2008 [ Fecha de acceso 3 de Octubre de 2013];58(4).URL Disponible en: http:// www.scielo.org.ve/pdf/at/v58n4/art08.pdf.

39. López FD. Inoculación con bacterias promotoras de crecimiento en cuatro especies leñosas de selva baja caducifolia trabajo [Tesis de grado].Mexico;2011.

40. Tripti, Vipin Kumar, Anshumali. Phosphate Solubilizing Activity of Some Bacterial Strains Isolated from Chemical Pesticide Exposed Agriculture Soil. International Journal of Engineering Research and Development [En línea] 2012 [Fecha de acceso 18 de Abril de 2013]; 3(9).URL Disponible en: http://www. ijerd.com/paper/vol3-issue9/A03090106.pdf.

41. Seshachala U, Tallapragada P. Phosphate solubilizers from the rhizosphere of piper nigrum 1 . in karnataka, India. Chilean Journal of agricultural research [En línea] 2012 [Fecha de acceso 23 de Marzo de 2014]; 72(3). URL disponible en: $\quad$ http://www.scielo.cl/scielo.php?script=sci_arttext\&pid $=$ S0718-58392012000300014.

42. Alvarez P, García S. Selección y evaluación de microorganismos solubilizadores de fosfatos en suelos calcáreos del Valle del Mantaro [En línea] 2012 [Fecha de acceso 15 de Febrero de 2014]; 1-25. URL disponible en: http://repositorio. educacionsuperior.gob.ec/bitstream/28000/260/1/T-SENESCYT-0029\%281\%29.pdf.

43. Rodríguez-Gámez O, Aguilera-Rodríguez I, Pérez-Silva RM. Adecuación de un micrométodo colorimétrico para la cuantificación de fósforo soluble en cultivos microbianos. Revista Cubana de Química [En línea] 2013[Fecha de acceso 24 de Marzo de 2014]; XXV (1). URL disponible en: http://ojs. uo.edu.cu/index.php/cq/article/viewFile/3349/2808.
44. Sunil Y, Keerti T, Lalit Singh R, Megha Kadam B, Sunil K, Iti G, Sharad T. Molecular Cloning of Phytase Gene from Bacillus subtilis NCIM-2712.Journal of phytology [En línea] 2011 [Fecha de acceso 3 de Noviembre de 2013];3(7). URL disponible en: http://journalphytology.com/index.php/phyto/ article/viewFile/7291/3760.

45. Bawane R, Tantwai K et al. Molecular Analysis of Phytase Gene Cloned from Bacillus subtilis. Advanced Studies in Biology [En línea] 2011 [Fecha de acceso 4 de Febrero de 2013]; 3(3). URL Disponible en: http://m-hikari.com/asb/asb2011/ asb1-4-2011/tantwaiASB1-4-2011.pdf.

46. Antelmann H, Scharf C, et al, Phosphate Starvation-Inducible Proteins of Bacillus subtilis: Proteomics and Transcriptional Analysis [En línea] 2000 [Fecha de acceso]; 182(16). URL Disponible en: http://www.ncbi.nlm.nih.gov/pmc/articles/ PMC94619/.

47. Robichon D, Maryvonne A, et al. Expression of a New Operon from Bacillus subtilis, ykzB-ykoL, under the Control of the TnrA and PhoP-PhoR Global Regulators [En línea] 2000 [Fecha de acceso 5 de Febrero de 2014]; 182(5). URL Disponible en: http://www.ncbi.nlm.nih.gov/pubmed/10671441.

48. Pragai Z, Harwood Colin R. Regulatory interactions between the Pho and $\triangle \mathrm{B}$-dependent general stress regulons of Bacillus subtilis.Microbiology [En línea] 2002 [ Fecha de acceso 26 de Mayo de 2013]. URL Disponible en: http://www.ncbi.nlm. nih.gov/pubmed/11988534.

49. E, E Nicholas et al.Genome-Wide Transcriptional Analysis of the Phosphate Starvation Stimulon of Bacillus subtilis [En línea] 2005 [Fecha de acceso 13 de Octubre de 2013]; 187(23). URL Disponible en: http://www.ncbi.nlm.nih.gov/ pubmed/16291680.

50. Makarewicz O, Dubrac S, et al. Dual Role of the PhoP-P Response Regulator: Bacillus amyloliquefaciens FZB45 Phytase Gene Transcription Is Directed by Positive and Negative Interactions with the phyC Promoter, [En línea] 2006 [Fecha de acceso 21 de Diciembre de 2013]; 188(19). URL Disponible en: http://jb.asm.org/content/188/19/6953.abstract.

51. Qinggang G, Shezeng et al. PhoR/PhoP two component regulatory system affects biocontrol capability of Bacillus subtilis NCD-2. Genetics and Molecular Biology [En línea] 2010 [Fecha de acceso 17 de Octubre de 2013]; 33(2). URL Disponible en: http://www.ncbi.nlm.nih.gov/pubmed/21637491. 